in the main only problems of inviscid flow for which exact solutions have been found are considered. No atternpts are made to assess the practical value of these theoretical results by comparison with experiment.

Chapter 1 gives the basic equations for different types of flow under various conditions and Chapter 2 is concerned with general theorems of use in the study of rotational flows, the hodograph method and the theory of characteristics. Chapter 3 is devoted to one-dimensional flow and contains sections on the effects of viscosity, heat conduction, simple wave propagation, shock reflexion and shock collision. A thorough presentation of the hodograph method, with a full discussion of recent advances in the theory, is included in Chapters 4 and 5 . Special attention is given to the treatment of shock waves and the book ends with an article on transonic flow. The main text is followed by an appendix of some forty pages of relevant and most interesting biographical and historical notes.

W. P. JONES

\section{THE METALLURGY OF MAGNESIUM}

The Physical Metallurgy of Magnesium and Its Alloys By Prof. G. V. Raynor. (International Series of Monographs on Metal Physics and Physical Metallurgy, Vol. 5.) Pp. ix +531. (London and New York: Pergamon Press, 1959.) 75s, net.

ROF. G. V. RAYNOR'S latest book provides the first predominantly theoretical survey of the subject of magnesium and its alloys, and it will most certainly form a valuable companion volume to those books published in recent years concerned mainly with the technological aspects of magnesium metallurgy. Both students and those concerned with development in industry will welcome this authoritative work, which is presented so as to give the theory first, followed by a review with examples of the alloy systems formed by magnesium.

The first part of the book (Chapters 1-7) deals with the fundamental nature of magnesium, its electronic constitution, and the effects of alloying. This section contains a masterly ten-page summary of the electron theory in general, before presenting a critical account of the qualitative and quantitative studies that have been made of the electronic constitution of magnesium. Magnesium is in a most interesting electronic state, and the author discusses, in a chapter on the lattice spacings of magnesium alloys, electronic interpretations of departures from Vegard's law, and lattice spacing changes due to temperature changes and to the application of tensile stress.

After a description of the general alloying behaviour of magnesium, in terms of the Hume-Rothery factors of atomic size, and relative- and electro-negative valency effects, an extensive account is given of the occurrence of intermediate phases in magnesium alloys. In particular, the structures of 'normal valency' compounds and Laves phases are considered in some detail, and the chapter is concluded by some pertinent observations as to why precipitation of these intermediate phases seldom leads to a high response to age-hardening in magnesium alloys.

This section of the book is concluded by an account of the deformational characteristics of single crystals and polycrystalline aggregates. After a fairly elementary description of edge and screw dislocations, the crystallography of slip and twinning in magnesium at room and elevated temperatures is outlined. Rupture, and the development of preferred orientations, are also considered, and an account of creep characteristics concludes the chapter.

The second part of the book (Chapters 8--17) describes and discusses the alloys of magnesium, considering the solute metals from the various groups of the Periodic Table in turn, stress being laid on those of present or potential importance. A selected list of references is provided at the end of each chapter - the literature being reviewed up to and including 1957. Rapid reference to this part of the book would be made easier by the more generous provision of sub-headings, as the alloys in each group are discussed.

A review of this nature emphasizes our ignorance of the fundamental mechanism of many technological processes, and many fields for further research are indicated. The suggestion of "submicroscopic precipitates" in, for example, the creep-resistant mag. nesium-cerium alloys will certainly whet the appetite of electron microscopists. There is, in fact, rather a dearth of photomicrographs in the book (there being only two sets), doubtless due to the high cost of their production. The value of the second set of micrographs is also reduced by the absence of any supplementary information-magnification, preparation, etc.

An account of the systems formed with gaseous elements or compounds concludes the review, an interesting discussion of the oxidation characteristics of the metal being included here. The final chapter summarizes the influence of alloying on the mechanical properties of magnesium. The book contains more than 200 diagrams - the phase diagrams being particularly well produced. This robust, well-bound volume will surely grace the shelves of students and research workers alike for many years to come.

J. W. Martin

\section{BIOLOGICAL PROPERTIES OF PHENOLS OF PLANT ORIGIN}

\section{The Pharmacology of Plant Phenolics}

Proceedings of a Symposium held at Oxford, April 1958. Edited by J. W. Fairbairn. Pp. ix +151 . (New York: Acadomic Press, Ine.; London: Academic Books, Ltd., 1959.) 6 dollars; $30 s$.

$T^{T}$ is not often that an attempt is made to present within the space of 150 pages a review of the biological properties of such a wide variety of chemical substances as the plant phenolics. It can indeed be argued that such a review can be of little value because the plant phenolics comprise a miscellaneous assortment of substances having nothing in common beyond the presence of an aromatic hydroxyl group, and some may feel that the choice of subject-matter has been made even more arbitrary by the inclusion of the chapter on adrenaline, noradrenaline and 5-hydroxytryptamine, since these substances are not of plant origin and owe their characteristic pharmacological properties to the presence of an amino-group rather than to the presence of a phenolic group.

Even if the fundamental pattern of this bookthe proceedings of a symposium held in Oxford last year-is regarded as slightly illogical, it represents, 